\title{
Three Methods and Principles for Lesson Preparation and Lecture for Young University Teachers
}

\author{
Hongquan Liu', a, Xiaoling Wang ${ }^{2, b}$, Chunling Chai ${ }^{1, c}$ and Xiping Zhang ${ }^{1, d}$
}

${ }^{1}$ School of Urban and Rural Construction, Hebei Agricultural University, Baoding, 071001, China;

${ }^{2}$ School of Horticulture, Hebei Agricultural University, Baoding, 071001, China.

alhqlhqlhq_2001@163.com, bwxl@hebau.edu.cn, c252813183@qq.com, d44096753@qq.com

\begin{abstract}
This template explains the methods and principles for lesson preparation and lecture for young university teachers. Before having class to prepare for the lessons well is the basic condition for splendid teaching; on having class to talk for the lessons well is the main primary method for splendid teaching; filling your heart with emotion as a young university teacher is the fundamental guarantee for splendid teaching.
\end{abstract}

Keywords: Splendid teaching; Prepare lesson; Method.

\section{论高校青年教师 “上好一堂课”的方法}

\section{刘宏权 ${ }^{1}$ ，王晓玲 ${ }^{2}$, 柴春岭'，张西平 ${ }^{1}$}

1. 河北农业大学城建学院, 保定 中国;

2. 河北农业大学园艺学院, 保定 中国

摘 要: 本文探讨了“上好一堂课”的方法途径, 并总结为“备” “讲” “情”：“备” 是“上 好一堂课” 的基本条件; “讲” 是 “上好一堂课” 的主要手段; “情” 是 “上好一堂课” 的 根本保证。

关键词：上好一堂课; 备课; 方法途径

\section{1. 前言}

“上好一堂课” 既是学生、学校和社会对教师的基本要求，也是我们教师自身的职业追 求。虽说教学是一门终将会留下缺憾的艺术, 但通过教师努力, 可以使缺憾少一点。关于如 何 “上好一堂课” 很多教师开展过相关的教学研究, 也取得了一些成果, 但还没有形成系统 的理论 $[1,2]$ 。作为一名高校青年教师, 现结合自身从教几年来的教学实践, 就如何 “上好一 堂课” 的途径方法, 谈下自己的体会。笔者认为作为高校青年教师要想 “上好一堂课” , 大 概离不开在 “备” “讲” “情”三字上下功夫、做文章。

\section{2. “备” 是 “上好一堂课” 的基本条件}

“上好一堂课” 课前要有清晰明确的教学目标, 要有悉心准备的教学内容, 要有灵活应 变的教学方法和有条不紊的教学流程, 所有这些都需要教师在课前为课堂教学做精心设计和 充分准备——备好课。备课不是简单对教材提前进行熟悉了解, 而是一个对教学内容知识整 合、消化、再创造的过程。所谓磨刀不误砍柴工, 备课多花些心思和时间, 对上好一堂课会 起到事半功倍的效果。如何备课呢? 有以下两方面是需要我们青年教师为课堂做好准备的:

2.1. “备” 内容

“备”内容包括备大纲和备教材。通过钻研课程大纲和教材, 明确课堂的教学目的, 明 确教学任务的轻重缓急和重点难点, 只有这样, 教学才能做到有的放矢和重点突出。明确了 
教学目的和教学内容, 教师也就清楚了教什么, 为什么教的问题。备教材不等同同于备课本, 教材除了课本还包括所有供教学所用的素材。高校教师在课堂上不能简单做课本知识的搬运 工, 做照本宣科的 “念老师”, 照搬课本内容会严重影响学生上课情绪和课堂教学效果。特 别对于高年级的专业课程, 课本上的有些知识点是明显老化过时的, 这就要求教师要关注专 业前沿动态, 及时对不合时宜知识点进行更新替换。同时, 教师应该把与课堂内容相关的专 业动态和案例揉加到课堂教学内容中, 这样教学内容既不能漫无边际而脱离大纲, 又不直于 课本。学生专业学习最终目的是服务社会, 教师也要适时把课堂讲授的方法在社会实践上的 应用及案例穿插到教学中, 让课堂知识英雄有用武之地, 学有所用, 变死的理论为活的知识。 学生通过课堂不但掌握了基础理论, 了解了前沿进展, 也明白了学有所用, 这样讲授内容就 比较全面了。

\section{2. “备” 学生}

教学包括教师的 “教” 和学生的 “学” 两个方面, 学生作为教师的教学对象, 教师必须 对班级学生情况有所掌握了解。只有了解学生, “备” 的内容才能符合学生的认知基础, 教 学才能做到因材施教, 教育才能遵循学生认知规律, 做到有的放矢。作为新时代的教师不能 两耳不闻窗外事, 一心只教圣贤书, 因为教书不是单向输出行为, 是双向互动行为, 教师要 根据课上学生对教授内容的情感反馈, 及时对教学方法做出调整。针对学生课上看手机、说 话、思想走私等现象, 若授课教师不管不顾, 一如既往专注于自己的讲课, 这样的教学是形 式上的教学, 不可能实现预期教学目标。面对课堂涣散, 教师应该去了解学生, 以平等的姿 态和学生交流, 并找到出现这种状况的原因, 找到症结所在, 再对症下药。“备” 学生来自 课堂和学生的接触, 对学生的了解, 更要在课堂外积极拓宽其他渠道, 如微信、电话、QQ空 间等都可以成为师生交流的渠道。“备” 学生看似对教学无直接关系, 好像无关紧要, 实则 关系着教学成败。试想若老师连上课班级的班长都不认识, 学生连授课老师姓什么都不清楚, 又怎能完成教学的双向互动, 又怎么能 “上好一堂课” 呢。

\section{3. “讲” 是 “上好一堂课” 的主要手段}

“上好一堂课” 是通过课堂讲授来实现的, 教学目标是通过讲授实现的, 教学过程本身 可以说就是讲授的过程, 可见 “讲” 对 “上好一堂课” 有多么重要。如何 “讲” 课才能取得 好的效果? 笔者可以从讲课逻辑和讲课语言两方面来谈一下:

3.1. “讲” 逻辑

讲课内容应逻辑清晰, 详略得当, 重点突出, 避免眉毛胡子一把抓, 逻辑混乱, 内容泛 泛。讲课逻辑是讲什么, 也是怎么讲; 讲课逻辑是要明确先讲什么, 后讲什么; 讲课逻辑是 确定课堂讲授如何开场, 如何结束。通过严谨的讲课逻辑, 把 “内容珍珠” 穿成一件精美项 链, 把看似无序的知识点连接形成专业理论。纲举目张, 有了讲课逻辑就有了讲课的主线, 一方面教师言之有物, 一方面学生学习有序, 利于 “教” “学”。

\section{2. “讲” 语言}

教师被称为 “灵魂的工程师”, 是传授知识, 更是向学生传授教师的观点和认知, 而知 识、观点和认知都需要通过语言来传达, 所以与其说讲课是一门艺术, 不如说讲课是一门语 言的艺术。教育家苏霍姆斯基认为 “教师的语言修养在极大程度上决定着学生课堂上学习的 效率” ，教学语言对 “上好一堂课” 的重要性是冊庸置疑的。教师授课语言首先应该是自信 的, 如果教师本身对所授内容不熟悉, 导致话语不坚定, 言语无力而犹疑, 作为学生怎么能 信服教师? 怎么能接受老师的观点? 所以教师授课语言应该是充满自信的。再者, 教师授课 语言应该是感情饱满的, 若教师音调一成不变, 声音平淡而不附加情感就像没有变奏的催眠 曲, 学生必然容易疲劳而导致思想走私, 也难以把握教学重点。情绪饱满而抑扬顿挫的启发 式授课, 适时适量加点风趣幽默的语言, 会有力调动学生上课情绪, 激发学生参与课堂积极 性, 也就提高了课堂教学的效率。 


\section{4. “情” 是 “上好一堂课” 的根本保证}

俗话说知之者不如好之者, 好之者不如乐之者, 爱一行是干好一行的保证, 教师行业也 是如此。热爱教学, 热爱专业, 喜爱学生, 喜爱课堂, 对职业的认同和感情是 “上好一堂课” 的根本保证。笔者认为教学本身不仅需要教师的真才实学, 还需要教师的真情实感。这里的 真情实感是教师对职业的情感, 也就是教师对专业的情感和对学生的情感。离开教师的职业 情感, 教学目标是难以真正实现的。

4.1. 专业 “情”

“兴趣是最好的老师”, 吸引学生对课堂的兴趣, 对专业的兴趣, 激发学生探索知识的 积极性和创造性是教师的重要职责。只有教师自己对专业充满了感情, 对专业知识传授有强 烈的感情和责任感, 那么透过教师充满专业情感的授课, 才能培养激发学生的专业兴趣。很 难想像一个不喜欢自身职业或专业的专业课教师能够上好专业课, 所以作为教师也应该有意 识的培养增强自己的专业意识和专业情感, 并通过课堂, 用自己的专业情感带动感染学生专 业学习的兴趣。

\section{2. 师生 “情”}

从某种意义上讲教师应该胸怀满腔教育的爱, 对学生的爱, 爱是教育的灵魂和动力。教 师和学生不是 “教” “学” 的契约关系, 而应建立亦师亦友的和谐师生关系。所谓师者所以 传道受业解惑也, 教师要教会学生知识, 更要教会学生专业, 教会学生做人。如果教师自己 教学定位仅仅限于要完成教学任务, 以挣工资养家糊口为目的走上讲台, 师生之间是不会建 立起来感情的, 学生也是难以信其道、信师道的。拓宽联系学生的渠道, 要让学生既感到老 师可敬, 又感到老师可亲。如此, 师生之间顺畅的沟通, 紧密的联系会真正有助于实现教学 相长和 “上好一堂课” 目的。

\section{5. 结语}

“上好一堂课”, 需要课前用心准 “备” : 是 “备大纲”、“备教材”、“备学生”, “备” 是 “上好一堂课” 的基础。“上好一堂课” 需要课上激情 “讲” 授：是 “讲逻辑”、 “讲方法”、“讲语言”, “讲”是 “上好一堂课”的手段。“上好一堂课” 需要对教师职 业付诸于真 “情” : “情” 是 “专业情”、“职业情”、“师生情”，“情”是 “上好一堂 课” 的保证。“备” “讲” “情” 是 “上好一堂课”的三字真经, 只要青年教师在 “备” “讲” “情”三字经上多用心实践, 即便效果一时可能还不能尽如人意, 但已然行进在 “上好一堂 课” 的正确道路上。

\section{致谢}

感谢河北农业大学第九批教学研究项目2015YB04对本论文的支持。

\section{References}

[1] Chunling Huang. Some Effective Methods and Principles for Lesson Preparation and Lecture. Journal of Higher Education Research. Vol35. No3, P.72-74.

[2] Jlanwei Zhang, Bailin Li. How to Improve Lectures Effect of Petroleum Chemistry for Young Teachers. Electric Power Education of China. (2011) No 8, P.106-107. 